\title{
PERHITUNGAN NILAI GARANSI MINIMUM MANFAAT KEMATIAN PADA ASURANSI UNIT-LINK
}

\author{
Ni Komang Ayu Sedana Dewi ${ }^{1 \S}$, I Nyoman Widana ${ }^{2}$, Luh Putu Ida Harini ${ }^{3}$ \\ ${ }^{1}$ Program Studi Matematika, Fakultas MIPA- Universitas Udayana [Email: ayusedana18@gmail.com] \\ ${ }^{2}$ Program Studi Matematika, Fakultas MIPA - Universitas Udayana [Email: nwidana@yahoo.com] \\ ${ }^{3}$ Program Studi Matematika, Fakultas MIPA - Universitas Udayana [Email: ballidah@gmail.com ] \\ ${ }^{\S}$ Corresponding Author
}

\begin{abstract}
The guarantee minimum on unit-linked insurance applies only to the most extreme situations of very bad rate of return on the fund's policyholders. One of the investment guarantees commonly used in unit-link is guaranteed minimum death benefit (GMDB). The final value under unit-linked insurance contracts can be expressed in terms of options that can be calculated using the Black-Scholes-Merton method. The purpose of this study is to determine the effect of age to the guarantee minimum value calculated using the Black-Scholes-Merton method. The calculation of GMDB value based on case simulation in this study resulted that the increasing age of the insured the greater the minimum guarantee value to be obtained.
\end{abstract}

Keywords: Black-Scholes-Merton, GMDB, Life Insurance, Minimum Guarantee, Unit-link Insurance.

\section{PENDAHULUAN}

Asuransi jiwa dapat menjadi jaminan finansial sehingga dapat meminimalkan akibat yang disebabkan dari risiko seperti kecelakaan, bencana alam dan kematian. Sebagian masyarakat saat ini lebih memilih untuk menginvestasikan uangnya karena dianggap lebih menguntungkan dibandingkan mengikuti asuransi jiwa tradisional. Investasi dapat dilakukan pada aset finansial seperti deposito, saham atau obligasi (Husnan, 2015). Untuk meningkatkan minat masyarakat dalam mengikuti asuransi jiwa, maka dikembangkan asuransi jiwa modern. Asuransi jiwa modern adalah suatu sistem asuransi yang mengombinasikan antara manfaat asuransi dan manfaat investasi. Salah satu dari jenis asuransi jiwa modern adalah asuransi unit-link. Asuransi unit-link merupakan asuransi jiwa yang mengkombinasikan manfaat asuransi dan investasi akan tetapi pada kontrak asuransi jiwa unit-link aset pemegang polis dan aset perusahaan asuransi tetap terpisah satu sama lain.
Risiko yang tidak dapat diobservasi dalam kontrak unit-link dan beberapa program pensiun biasanya muncul dari garansi keuangan pada saat jatuh tempo atau kematian, garansi ini sangat mirip dengan pertukaran opsi finansial. Salah satu jenis opsi yang ada pada finansial adalah opsi Eropa. Menurut Changki (2008), pada asuransi unit-link penerima polis juga menerima sebuah garansi minimum. Pembayaran garansi minimum berdasarkan kontrak unit-link biasanya berupa aspek yang relatif kecil dari total pembayaran berdasarkan polis, karena garansi hanya diterapkan pada situasi yang paling ekstrem dari tingkat pengembalian yang sangat buruk pada dana pemegang polis. Salah satu jaminan investasi yang biasanya digunakan dalam asuransi unitlink yaitu guaranteed minimum death benefit (GMDB) atau garansi minimum yang diberikan pada saat pemegang polis meninggal selama masa kontrak. Sehingga tujuan dari penelitian ini adalah untuk mengetahui hasil hitung nilai garansi minimum manfaat kematian saat pemegang polis berusia $15,20,25,30,35,40$, $45,50,55$ dan 60 tahun dan mengetahui 
pengaruh usia dalam nilai garansi minimum manfaat kematian pada asuransi unit-link.

\section{TINJAUAN PUSTAKA}

Menurut Sembiring (1986), asuransi jiwa merupakan usaha kerjasama atau koperasi dari sejumlah orang yang sepakat memikul kesulitan keuangan bila terjadi musibah terhadap salah seorang anggotanya. Asuransi jiwa dapat dibagi menjadi dua yaitu asuransi jiwa tradisional dan asuransi jiwa modern (Dickson et al, 2009). Menurut Mandal (2016), kontrak asuransi jiwa tradisional adalah jenis kontrak yang paling mendasar dengan premi dan manfaat yang akan didapat telah ditentukan. Terdapat empat bentuk asuransi tradisional yaitu asuransi berjangka, asuransi seumur hidup, asuransi dwiguna, dan asuransi tertunda. Sedangkan asuransi modern merupakan asuransi yang mengkombinasikan antara asuransi jiwa tradisional dengan manfaat investasi. Terdapat tiga bentuk asuransi jiwa modern yaitu asuransi unit-link, asuransi unitzed with profit, dan asuransi universal. Perbedaan asuransi unit-link dengan asuransi unitzed with profit dan asuransi universal adalah pada kontrak asuransi unit-link aset pemegang polis dan aset perusahaan asuransi tetap terpisah satu sama lain sedangkan pada asuransi modern lainnya aset perusahaan dan aset pemegang polis digabungkan.

Asuransi jiwa unit-link merupakan asuransi jiwa modern yang menggabungkan produk asuransi yaitu antara asuransi jiwa dan investasi, dengan manfaat dibayarkan pada akhir kontrak. Menurut Muyasarah (2010) karakteristik asuransi jiwa unit-link sebagai berikut: 1) Asuransi jiwa unit-link dapat digunakan sebagai alat tabungan dan proteksi. 2) asuransi jiwa unit-link memiliki beberapa jenis investasi yang beragam mulai dari konservatif, moderat, dan agresif. 3) Biaya proteksi umumnya terpenuhi dengan membebankan biaya sesuai dengan usia dan besarnya proteksi. 4) Asuransi unit-link memiliki sifat transparan. 5) Setiap pemegang polis mendapatkan laporan besar premi yang harus dibayarkan pada tahun pertama serta mendapat data hasil investasi yang diperoleh selama setahun berjalan. 6) Asuransi unit-link bersifat fleksibel.

Kontrak unit-link menawarkan beberapa elemen partisipasi dalam indeks atau dana yang mendasarinya dan menawarkan juga satu atau lebih garansi. Tanpa garansi, asuransi unit-link tidak melibatkan risiko bagi perusahaan asuransi, yang hanya bertindak sebagai pengelola dana pemegang polis. Garansi adalah kombinasi dari penyertaan modal dan pembagian jumlah tetap yang memberikan risiko bagi perusahaan asuransi. Risiko jumlah tetap ini pada umumnya termasuk ke salah satu kategori utama berikut (Hardy, 2003): Garansi minimum manfaat jatuh tempo (GMMB), Garansi minimum manfaat kematian (GMDB), Garansi minimum manfaat akumulasi (GMAB), Garansi minimum manfaat penyerahan (GMSB), Garansi minimum manfaat pendapatan (GMIB).

Nilai akhir berdasarkan kontrak asuransi yang terkait dengan asuransi unit-link dapat dinyatakan dalam bentuk opsi. Salah satu model yang dapat digunakan dalam menentukan harga opsi adalah model Black-Scholes-Merton atau biasa disebut Model Black-Scholes. Model Black-Scholes-Merton untuk menetukan harga opsi menggunakan waktu kontinu. Menurut Hardy (2003) bentuk kontrak opsi yang paling sederhana adalah opsi put dan opsi call. Persamaan yang digunakan untuk menghitung harga opsi put dan opsi call secara berturut-turut yaitu

$$
\begin{gathered}
c(k)=S_{k} \Phi\left(d_{1}(k)\right)-K e^{-r(T-k)} \Phi\left(d_{2}(k)\right) \\
p(k)=K e^{-r(T-k)} \Phi\left(-d_{2}(k)\right)-S_{k} \Phi\left(-d_{1}(k)\right)
\end{gathered}
$$

Tidak semua polis asuransi unit-link memuat garansi minimum pada manfaat jatuh tempo, namun sebagian besar memuat garansi minimum pada manfaat kematian. Garansi yang paling umum saat kematian adalah manfaat kematian tetap atau peningkatan minimum kematian (Dickson et al., 2009). Misalkan suatu kontrak asuransi pada saat $n$ tahun untuk seorang yang berumur $x$ tahun, dengan fungsi payoff disimbolkan dengan $h(k)$. Jika $x$ meninggal saat usia $x+k$ tahun dengan $k<n$. Maka nilai sekarang yang diharapkan atau nilai dari opsi pada asuransi unit-link adalah 
$v(0, k)=E_{0}^{Q}\left[e^{-r k} h(k)\right]$

dengan $h(k)$ dapat dirumuskan sebagai

$h(k)=\max \left(P-F_{k}, 0\right)$

dengan $F_{k}$ menyatakan nilai dana pemegang polis pada saat $k$ tahun. Proses nilai dana $\left\{F_{k}\right\}_{k \geq 0}$ dapat dianggap sebagai proses harga saham, dan $P$ diketahui dengan jumlah tetap. Payoff $h(k)$ sama dengan nilai akhir pada saat $k$ tahun opsi put Eropa dengan harga tebus $P$. Simbol $Q$ pada persamaan (1) menunjukan ukuran risiko netral untuk proses harga unit yang diinvestasikan dari dana pemegang polis. Densitas peluang ketika seorang yang berusia $x$ meninggal saat usia $x+k$ tahun adalah ${ }_{k} p_{x} \mu_{x+k}$, sehingga jumlah yang harus disiapkan untuk garansi minimum manfaat kematian dinotasikan dengan $\pi(0)$, dengan rata-rata kemungkinan meninggal pada usia $x+k$, sehingga

$\pi(0)=\int_{0}^{n} v(0, k)_{k} p_{x} \mu_{x+k} d k$

Jika manfaat kematian dibayarkan pada akhir bulan kematian dan bukan saat kematian, maka nilai garansi menjadi,

$\pi(0)=\sum_{w=1}^{12 n} v(0, w / 12)_{\frac{w-1}{12} \mid \frac{1}{12}} q_{x}$

Sehingga untuk menghitung garansi minimum manfaat kematian pada asuransi unit-link digunakan persamaan (4).

\section{METODE PENELITIAN}

Data yang digunakan dalam penelitian ini berupa data peluang hidup orang yang berusia 15 sampai 65 tahun mengikuti tabel mortalita TASPEN tahun 2012, data harga dana unit Prulink Rupiah Cash Fund Prudential (4 Januari 2016 sampai 3 Pebruari 2017) yang diperoleh dari Prudential Indonesia. Suku bunga yang digunakan pada penelitian ini adalah suku bunga bebas risiko dari Bank Indonesia (BI) yaitu $6,5 \%$. Langkah analisis data yang harus dilakukan dalam penelitian ini adalah

1) Menghitung nilai peluang kematian bulanan $\left({ }_{s} q_{x}\right)$ menggunakan persamaan

$$
{ }_{s} q_{x}=s q_{x}
$$

2) Menghitung volatilitas menggunakan data historis a. Mengambil data harga dana unit pada Prulink Rupiah Cash Fund Prudential.

b. Menghitung return dana unit pada waktu $k\left(R_{k}\right)$ menggunakan persamaan $R_{k}=\ln \left(\frac{s_{k}}{s_{k-1}}\right)$

c. Menghitung tingkat keuntungan yang diharapkan $(\bar{R}) \quad$ menggunakan persamaan

$\bar{R}=\frac{\sum_{k=1}^{n} R_{k}}{n}$

d. Menghitung volatilitas historis dana unit menggunakan persamaan

$$
\sigma=\sqrt{(\mathrm{n}) \frac{\sum_{\mathrm{k}=1}^{\mathrm{n}}\left[\mathrm{R}_{\mathrm{k}}-\overline{\mathrm{R}}\right]^{2}}{(\mathrm{n}-1)}}
$$

3) Menghitung opsi put tipe Eropa dengan menggunakan formula Black-ScholesMerton pada asuransi unit-link.

a. Menghitung nilai dana pemegang polis pada saat $k\left(F_{k}\right)$.

b. Menghitung nilai payoff $(h(k))$ menggunakan persamaan (2)

c. Menghitung nilai $d_{1}(0, k)$ dan $d_{2}(0, k)$ dalam persamaan

$$
\begin{aligned}
& d_{1}(k)=\left(\frac{\log \left(S_{k} / K\right)+\left(r+\sigma^{2} / 2\right)(T-k)}{\sigma \sqrt{T-k}}\right) \\
& d_{2}(k)=d_{1}(k)-\sigma \sqrt{(T-k)}
\end{aligned}
$$

d. Menghitung nilai distribusi normal standar $(\Phi)$ dari $-d_{1}(0, k)$ dan $-d_{2}(0, k)$

e. Menghitung nilai opsi put Eropa $(v(0, k))$ menggunakan persamaan (1).

4) Menghitung nilai garansi minimum manfaat kematian pada asuransi unit-link.

a. Menghitung peluang kematian yang tertunda $\left(k-\frac{1}{12} \mid \frac{1}{12} q_{x}\right)$.

b. Menghitung nilai garansi minimum manfaat kematian dari premi yang dibayarkan $(\pi(0))$ menggunakan persamaan (4)

\section{HASIL DAN PEMBAHASAN}

Sebelum mengetahui tentang pengaruh usia terhadap nilai garansi minimum yang didapat akan diuraikan perhitungan nilai garansi minimum manfaat kematian atau Guarantee Minimum Death Benefit (GMDB) untuk produk 
asuransi unit-link. Khususnya dana unit Prulink Rupiah Cash Fund dengan kontrak selama 5 tahun untuk usia $15,20, \ldots, 60$ tahun. Premi yang dibayarkan adalah premi tunggal sebesar Rp42.000.000,00 yang telah diinvestasikan dalam dana unit. Biaya pengelolaan dana investasi ini adalah $0,75 \%$ per bulan dan tingkat bunga $6,5 \%$ pertahun. Uang pertanggungan (benefit) yang akan didapat oleh peserta asuransi unit-link adalah sebagai berikut.

a. Apabila peserta tetap hidup sampai kontrak asuransi berakhir maka peserta akan mendapatkan uang pertanggungan sebesar nilai dari saldo dana unit yang dimiliki yang dihitung berdasarkan harga dana unit pada saat akhir kontrak.

b. Apabila peserta tersebut meninggal dunia sebelum kontrak berakhir maka uang pertanggungan yang didapat adalah manfaat asuransi ditambah dengan nilai dari saldo dana unit yang peserta miliki pada saat peserta meninggal.

Berikut adalah langkah-langkah yang dilakukan untuk menghitung nilai garansi minimum.

1. Menghitung nilai peluang kematian bulanan $\left({ }_{s} q_{x}\right)$

Nilai dari ${ }_{s} q_{x}$ diperoleh dengan menggunakan persamaan (5) dengan nilai $q_{x}$ yang diperoleh dari Tabel Mortalitas TASPEN 2012. Untuk ilustrasi kasus yang dihitung peluang kematian bulanan untuk $x=15$ tahun.

Untuk $s=\frac{1}{12}$, diperoleh

$$
\begin{aligned}
\frac{1}{12} q_{15} & =\frac{1}{12} \times q_{15} \\
& =\frac{1}{12} \times 0.0002616 \\
& =0.0000218
\end{aligned}
$$

Sehingga untuk peluang kematian bulan pertama pada saat usia 15 tahun adalah 0.000218. Cara yang sama digunakan untuk menghitung peluang kematian dibulan berikutnya sampai dengan pada bulan ke-11.

\section{Menghitung Nilai Volatilitas Historis}

Perhitungan garansi minimum memerlukan nilai dari volatilitas. Volatilitas pada penelitian ini dihitung berdasarkan data historis dari dana unit Prulink Rupiah Cash Fund yang diperoleh dari Prudential Indonesia.

a) Menghitung Nilai Return dari Dana Unit

Nilai return dari dana unit dihitung menggunakan persamaan (6)

Untuk $t=1$

$$
\begin{aligned}
R_{1} & =\ln \left(\frac{S_{1}}{S_{1-1}}\right) \\
\Leftrightarrow R_{1} & =\ln \left(\frac{S_{1}}{S_{0}}\right) \\
& =\ln \left(\frac{3082.58}{3081.82}\right) \\
& =\ln (1.000247) \\
& =0.000247
\end{aligned}
$$

Perhitungan yang sama digunakan untuk $t$ selanjutnya.

b) Menghitung Tingkat Keuntungan yang Diharapkan

Tingkat keuntungan yang diharapkan $(\bar{R})$ dapat dihitung menggunakan persamaan (7)

$$
\begin{aligned}
\bar{R} & =\frac{\sum_{t=1}^{272} R_{t}}{272} \\
& =\frac{0.000247+0.000279+\cdots+0.000192}{272} \\
& =\frac{0.064084}{272} \\
& =0.0002356
\end{aligned}
$$

Jadi tingkat keuntungan yang diharapkan adalah 0.0002356 .

c) Menghitung Volatilitas Historis

Sebelum menghitung volatilitas historis menggunakan persamaan (8), hitung nilai $\sum_{\mathrm{t}=1}^{272}\left[\mathrm{R}_{\mathrm{t}}-\overline{\mathrm{R}}\right]^{2}$.

Untuk $t=1$

$$
\begin{aligned}
{\left[\mathrm{R}_{1}-\overline{\mathrm{R}}\right]^{2} } & =[0.000247-0.0002356]^{2} \\
& =[0.000011]^{2} \\
& =0.00000000012
\end{aligned}
$$

Setelah diperoleh nilai $\left[\mathrm{R}_{\mathrm{t}}-\overline{\mathrm{R}}\right]^{2}$ untuk setiap $t$, kemudian jumlahkan nilai tersebut.

$$
\begin{aligned}
\sum_{\mathrm{k}=1}^{272}\left[\mathrm{R}_{\mathrm{t}}-\overline{\mathrm{R}}\right]^{2}= & 0.00000000012 \\
& +0.00000000188+\cdots \\
& +0.00000000192 \\
= & 0.0019721
\end{aligned}
$$

Kemudian dapat dihitung volatilitas

$$
\begin{aligned}
\sigma & =\sqrt{(272+1) \frac{\sum_{t=1}^{272}\left[R_{t}-\bar{R}\right]^{2}}{(272-1)}} \\
& =\sqrt{(273) \frac{0.0019721}{(271)}}
\end{aligned}
$$




$$
\begin{aligned}
& =\sqrt{0.001987} \\
& =4 \%
\end{aligned}
$$

Jadi nilai volatilitas dari data historis dana unit Prulink Rupiah Cash Fund yang diperoleh adalah $4 \%$.

3. Menghitung Opsi Put Tipe Eropa

a) Menghitung Nilai Dana Pemegang Polis

Dana pemegang polis dalam kasus ini adalah hasil kali dari premi yang dibayarkan, harga dana unit pada saat $k$ dan 1 dikurangi biaya pengelolaan dana unit yang dipilih atau dapat ditulis dengan

$F_{k}=P S_{k}(1-m)^{12 k}$

b) Menghitung Nilai

Pertambahan

Pengasuransi

Tambahan pengasuransi dapat dihitung menggunakan persamaaan (2) karena pada kontrak ini premi dimajemukan secara terusmenerus maka persamaan (2) menjadi

$h(k)=\max \left(P e^{0.065 k}-F_{k}, 0\right)$

dengan mensubtitusikan persamaan (10)

maka persamaan (11) menjadi

$$
\begin{gathered}
h(k)=P(1-m)^{12 k} \max \left(\frac{e^{0.065 k}}{(1-m)^{12 k}}-\right. \\
\left.S_{k}, 0\right)
\end{gathered}
$$

maka diketahui pada ilustrasi kasus ini harga tebus yang didapat adalah $\frac{e^{0.065 k}}{(1-m)^{12 k}}$. Karena sebelumnya sudah diketahui harga tebusnya $\frac{e^{0.065 k}}{(1-m)^{12 k}}$ dan suku bunga bebas resiko 0.065 , apabila $v(0, k)$ didefinisikan sebagai nilai pada saat 0 dari garansi pada waktu ke$k$ sehingga menjadi

$$
\begin{aligned}
& v(0, k)=P\left(\Phi\left(-d_{2}(0, k)\right)-\right. \\
& \left.S_{0}(1-m)^{12 k} \Phi\left(-d_{1}(0, k)\right)\right)
\end{aligned}
$$

c) Menghitung nilai $\boldsymbol{d}_{\mathbf{1}}(\mathbf{0}, \boldsymbol{k})$ dan $\boldsymbol{d}_{\mathbf{2}}(\mathbf{0}, \boldsymbol{k})$

Menghitung nilai $d_{1}(0, k)$ dan $d_{2}(0, k)$ menggunakan persamaan (9). dengan menggunakan harga tebus yang diperoleh menjadi

$$
\begin{aligned}
& d_{1}(0, k)=\left(\frac{\log \left(\frac{(1-m)^{12 k}}{e^{0.065 k}}\right)+\left(r+\sigma^{2} / 2\right)(k)}{\sigma \sqrt{k}}\right) \\
& d_{2}(0, k)=d_{1}(0, k)-\sigma \sqrt{(k)} \\
& \text { Untuk } k=\frac{1}{12} \text { diperoleh }
\end{aligned}
$$

$$
\begin{aligned}
& d_{1}(0, k) \\
& =\left(\frac{\log \left(\frac{(1-m)^{12 k}}{e^{0.065 k}}\right)+\left(r+\sigma^{2} / 2\right)(k)}{\sigma \sqrt{k}}\right) \\
& =-0.64619
\end{aligned}
$$

Selanjutnya akan dihitung $d_{2}(0, k)$ untuk $k=\frac{1}{12}$ sebagai berikut

$$
\begin{gathered}
d_{2}(0, k)=d_{1}(0, k)-\sigma \sqrt{(k)} \\
=-0.65774
\end{gathered}
$$

Perhitungan yang sama untuk $k$ lainnya.

d) Menghitung nilai $\boldsymbol{\Phi}\left(-\boldsymbol{d}_{\mathbf{1}}(\mathbf{0}, \boldsymbol{k})\right)$ dan $\Phi\left(-d_{2}(0, k)\right)$

Dengan memasukan nilai volatilitas $4 \%$, dan menggunakan formula normsdist pada Microsoft Excel 2007 diperoleh

Untuk $k=\frac{1}{12}$

$$
\begin{gathered}
\Phi\left(-d_{1}(0,1 / 12)\right) \\
=1-\text { normsdist }(-0.64619) \\
=0.740923 \\
\Phi\left(-d_{2}(0,1 / 12)\right) \\
=1-\text { normsdist }(-0.65774) \\
=0.74465
\end{gathered}
$$

Perhitungan tersebut juga berlaku untuk $k$ lainnya.

e) Menghitung Nilai Opsi Put Tipe Eropa $\boldsymbol{v}(\mathbf{0}, \boldsymbol{k})$

Setelah diperoleh nilai $\Phi\left(-d_{1}(0, k)\right)$ dan $\Phi\left(-d_{2}(0, k)\right)$, dengan menggunakan persamaan (13), sehingga untuk $k=\frac{1}{12}$ diperoleh

$$
\begin{aligned}
v(0, k)= & 42000000\left(\Phi\left(-d_{2}\left(0, \frac{1}{12}\right)\right)-1 \times\right. \\
& \left.(1-0.0075)^{12\left(\frac{1}{12}\right)} \times \Phi\left(-d_{2}\left(0, \frac{1}{12}\right)\right)\right) \\
= & 389823.07
\end{aligned}
$$

Untuk $k$ yang lain menggunakan cara yang sama seperti sebelumnya.

4. Menghitung Nilai Garansi Minimum Manfaat Kematian

a) Menghitung peluang kematian yang tertunda

Perhitungan peluang kematian yang tertunda ini menggunakan persamaan

$$
{ }_{u \mid t} q_{x}={ }_{u} p_{x}-{ }_{u+t} p_{x}
$$


Untuk ilustrasi kasus pada penelitian ini maka diperoleh

$$
\begin{aligned}
{ }_{k-\frac{1}{12} \mid \frac{1}{12}} q_{x} & ={ }_{k-\frac{1}{12}} p_{x}-{ }_{k-\frac{1}{12}+\frac{1}{12}} p_{x} \\
= & { }_{k-\frac{1}{12}} p_{x}-{ }_{k} p_{x} \\
= & \left(1-{ }_{k-\frac{1}{12}} q_{x}\right)-\left(1-{ }_{k} q_{x}\right) \\
& ={ }_{k} q_{x}-{ }_{k-\frac{1}{12}} q_{x}
\end{aligned}
$$

Sehingga untuk $x=15$ dengan $k=\frac{1}{12}$ diperoleh

$$
\begin{aligned}
\frac{1}{12}-\frac{1}{12} \mid \frac{1}{12} q_{15} & =\frac{1}{12} q_{15}-\frac{1}{12}-\frac{1}{12} q_{15} \\
& =0.000218-0 \times q_{15} \\
& =0.000218
\end{aligned}
$$

Setelah diperoleh nilai peluang hidup yang tertunda untuk semua peserta asuranasi. Kemudian dapat dihitung nilai garansi minimum manfaat kematian.

b) Menghitung Nilai Garansi Minimum

\section{Manfaat Kematian}

Perhitungan nilai garansi minimum manfaat kematian dihitung menggunakan persamaan (2.50). Untuk ilustrasi kasus usia $x=15$ diperoleh

$$
\begin{aligned}
& \pi(0)=\sum_{w=1}^{60} v(0, w / 12)_{\frac{w-1}{12}} \mid \frac{1}{12} q_{15} \\
& =v(0,1 / 12)_{1-1}{ }_{12} q_{15}+\cdots \\
& \frac{1-1}{12} \mid \frac{1}{12} \\
& +v(0,60 / 12)_{\frac{1-1}{12} \mid \frac{1}{12}} q_{15} \\
& =389823.07 \times 0.0000218+\cdots+ \\
& 14867757 \times 0.0000307 \\
& =8.4981429+\cdots+456.98529 \\
& =13198.96
\end{aligned}
$$

Dengan demikian untuk seorang yang berusia $x=15$ garansi minimum yang diperoleh adalah Rp. $13.855,38$ atau $0,03 \%$ dari premi yang dibayarkan. Untuk semua usia tertanggung juga berlaku mengikuti perhitungan tersebut. Sehingga untuk usia 15, 20, 25, 30, 35, 40, 45, 50, 55, dan 60 tahun diperoleh nilai garansi minimum sesuai dengan Tabel 1.
Tabel 1. Nilai Garansi Minimum Manfaat Kematian

\begin{tabular}{|c|c|c|}
\hline $\begin{array}{c}\text { Usia } \\
\text { (tahun) }\end{array}$ & Nilai GMDB & $\begin{array}{c}\text { Presentase dari } \\
\text { Premi }\end{array}$ \\
\hline 15 & Rp. $13.855,38$ & $0,03 \%$ \\
\hline 20 & Rp. 21.286,83 & $0,05 \%$ \\
\hline 25 & Rp. 32.682,32 & $0,07 \%$ \\
\hline 30 & Rp. 50.236,2 & $0,11 \%$ \\
\hline 35 & Rp. 77.162,18 & $0,18 \%$ \\
\hline 40 & Rp. $118.499,4$ & $0,28 \%$ \\
\hline 45 & Rp. 181.932,8 & $0,43 \%$ \\
\hline 50 & Rp. 279.207,2 & $0,66 \%$ \\
\hline 55 & Rp. 428.219,6 & $1,01 \%$ \\
\hline 60 & Rp. 656.121,3 & $1,56 \%$ \\
\hline
\end{tabular}

Berdasarkan Tabel GMDB dapat dilihat bahwa nilai garansi minimum untuk usia tertanggung 15 tahun Rp. 13.855,38 dan seterusnya. Presentase dari premi yang dimaksud pada tabel tersebut adalah berapa persen garanasi yang didapat dari premi yang dibayarkan oleh tertanggung.

\section{SIMPULAN DAN SARAN}

Berdasarkan hasil perhitungan nilai garansi minimum manfaat kematian untuk sepuluh usia tertanggung dapat dilihat bahwa semakin bertambahnya usia tertanggung semakin besar pula nilai garansi minimum yang diperoleh. Hal ini terjadi dikarenakan oleh semakin bertambahnya usia tertanggung semakin tinggi pula peluang kematian dari seorang tertanggung. Dengan demikian usia tertanggung memengaruhi nilai garansi minimum yang akan diterima saat akhir bulan tertanggung meninggal pada masa kontrak tersebut.

Untuk penelitian selanjutnya, penulis menyarankan untuk melakukan perhitungan pada jenis garansi minimum yang lainnya. Karena penelitian yang penulis telah lakukan hanya menghitung nilai garansi minimum manfaat kematian (GMDB) sedangkan ada beberapa jenis garansi minimum yang dapat dihitung. 


\section{DAFTAR PUSTAKA}

Changki, Kim. 2008. The Impacts of Guaranteed Minimum Death Benefit Option on the Profit Margins of Unit-linked Product. Paper No.2008ACTL19. UNSW Australian School of Business.

https://papers.ssrn.com/sol3/Delivery.cfm/S SRN_ID1317459_code858089.pdf?abstracti $\underline{\mathrm{d}=1317459 \& \text { mirid }=1}$

Dickson, D.C.M., Hardy, M. R and Waters, H.R. 2009. Actuarial Mathematics for Life Contingent Risk. New York: Cambridge University Press.

Hardy, M. 2003. Investment Guarantees: Modelling and Risk Management for EquityLinked Life Insurance. USA: Jhon Wiley \& Sons,Inc.

http://shora.tabriz.ir/Uploads/83/cms/user/Fi le/657/E_Book/Economics/Investment\%20

Guarantees.pdf
Husnan, S. 2015. Dasar-dasar Teori Portofolio dan Analisis Sekuritas Edisi Kelima. Yogyakarta: UUP STIM YKPM

Mandal, Satrajit. 2016. Unit-linked Insurance Plans and Their Applications in India. Thesis. Tartu: University of Tartu. http://dspace.ut.ee/bitstream/handle/10062/5 2450/mandal_satrajit_msc_2016.pdf

Muyasarah, S. 2010. Analisis SWOT Terhadap Produk Asuransi Unit-link (Studi Pada PT. ASURANSI TAKAFUL KELUARGA). Skripsi. Universitas Islam Negeri Syarif Hidayatullah, Jakarta. http://repository.uinjkt.ac.id/dspace/bitstrea $\mathrm{m} / 123456789 / 2468 / 1 / \mathrm{SITI} \% 20 \mathrm{MUYASAR}$ AH-FSH.pdf

Sembiring, R. K. 1986. Buku Materi Pokok Asuransi I modul 1-9.J Universitas Terbuka. 